\title{
Evaluation of Cell Proliferation and Apoptosis in Placentas of Rats with Severe Diabetes
}

\author{
Marilza Vieira Cunha Rudge ${ }^{1 *}$, Elaine Costa $^{1}$, Luis Fernando Barbisan ${ }^{2}$, Débora Cristina \\ Damasceno $^{1}$, Aline Bueno ${ }^{1}$, Felipe Hiroshi Saito ${ }^{1}$, Iracema Mattos Paranhos Calderon ${ }^{1}$ and \\ Marcela Marcondes Pinto Rodrigues ${ }^{1}$ \\ ${ }^{1}$ Laboratório de Pesquisa Experimental de Ginecologia e Obstetrícia; Departamento de Ginecologia e Obstetrícia; \\ Universidade Estadual Paulista; 18618-000; Botucatu - SP - Brasil. ${ }^{2}$ Departamento de Morfologia; Instituto de \\ Biociências de Botucatu; Universidade Estadual Paulista;18618-000; Botucatu - SP-Brasil
}

\begin{abstract}
The aim of this work was to analyze the cell proliferation and apoptosis indexes on the $18^{\text {th }}$ and $21^{\text {st }}$ days of pregnancy of diabetic rats and to correlate with maternal glycemia and perinatal outcomes. Placentas from 20 Wistar rats were collected and divided into four experimental groups: control and diabetic of 18 and 21 days of pregnancy. The cell proliferation was analyzed using the PCNA expression and apoptosis by the TUNEL method. It was observed that PCNA and TUNEL indexes decreased from day 18 to 21 of pregnancy in the placentas of diabetic rats and these values were lower than control groups. Diabetic dams presented higher percentage of small for pregnancy age (SPA) fetuses. However, there was no difference between the PCNA and TUNEL indexes in SPA and $N$-SPA fetuses in all the groups and these indexes were not correlated to maternal glycemic. Thus, placental cell proliferation and apoptosis did not interfere in the intrauterine growth restriction.
\end{abstract}

Key words: diabetes, cell proliferation, apoptosis, placenta, rat, IUGR

\section{INTRODUCTION}

The maintenance of structural and functional integrity of placental tissue involves a highly regulated cellular turnover that is dependent upon a delicate balance involving the cell proliferation, differentiation and death (Benirschke and Kaufmann 2000). These events are involved in programmed cell death by apoptosis (Chan et al. 1999). Apoptosis is a widespread process, occurring primarily in tissues during the development or morphological change (Burleigh et al. 2004) and is intimately involved in placental homeostasis, growth and remodeling. The apoptotic rates increase progressively during normal pregnancy as part of normal placental development. Moreover, apoptosis increases in pregnancies complicated by some pathologies such as preeclampsia, diabetes and fetal growth restriction (Cobellis et al. 2007). The apoptotic morphology includes loss of surface membrane specializations and cell anchorage concomitant with blebbing, chromatin condensation with nuclear fragmentation and cytoplasmic condensation with cell shrinkage (Levy and Nelson 2000). This event is energy-dependent and detected by terminal transferase-mediated in situ end labeling (TUNEL) (Kim et al. 2006). Investigations with animal models have also shown that in streptozotocin-induced diabetic rats, placental growth is markedly altered, exhibiting a

*Author for correspondence: marilzarudge@ig.com.br 
notable decrease in apoptotic and proliferation indexes (Rudge et al. 2000).

Proliferating cell nuclear antigen (PCNA) protein is one of the central molecules responsible for decisions of life and death of the cell. PCNA is also involved in DNA repair, including nucleotide excision repair, base excision repair and mismatch repair. It is an essential molecule in the life of single cellular organisms, and then became a protein critical for the survival of multicellular organisms (Paunesku et al. 2001). Studies in humans that explore the responsible mechanism for alterations caused by the maternal diabetes during pregnancy are limited not only due to ethical reasons, but also due to the multiplicity of uncontrolled variables that may modify the intrauterine environment and cause potential effects on congenital malformations, such as feeding behavior, socioeconomic factors, nutritional status, and genetic factors (LópezSoldado and Herrera 2003). Thus, there is need for development of appropriate animal models to better understand the diagnosis, pathology and treatment of diabetes. To reproduce the clinical uncontrolled type-1 diabetes, experimental models are used to obtain the severe diabetes (glycemia $>300 \mathrm{mg} / \mathrm{dL}$ ) (Damasceno et al. 2002; Eriksson et al. 2000, 2003; Rudge et al. 2007; Volpato et al. 2008; de Souza et al. 2009). This type of diabetes is a model of IUGR (Volpato et al. 2008, Rudge et al. 2007; de Souza et al., 2009) and is associated with higher placental weight and index (de Souza et al. 2009).

Calderon et al. (1999) observed that maternal hyperglycemia altered the maturation of the placenta, characterizing it as insufficient in their nutritive function, due to higher incidence of fetuses classified as small for pregnancy age (SPA). Many studies have reported apoptosis in placentas of fetuses with IUGR (Smith et al., 1997b; Kudo et al., 2000; Levy et al. 2002). Increased placental thickness and content of DNA and proteins suggest that placentas of rats with severe diabetes may have increased cell proliferation. Considering that severe diabetes is a model of IUGR, there was interest in studying how antagonistic mechanisms as apoptosis and cellular proliferation can coexist in placentas of rats with severe diabetes. The aim of this study was to analyze the cell proliferation and apoptosis indexes on the $18^{\text {th }}$ and $21^{\text {st }}$ days of pregnancy of diabetic rats and to correlate with maternal glycemic and perinatal outcomes.

\section{MATERIAL AND METHODS}

\section{Animals}

Wistar rats obtained from UNESP - Univ Estadual Paulista, São Paulo State, Brazil were maintained in an experimental room under controlled conditions (temperature of $22 \pm 2^{\circ} \mathrm{C}$, humidity of $50 \pm 10 \%$ and 12-hlight/dark cycle) with ad libitum access to commercial food (Purina chow ${ }^{\circledR}$ ) and tap water. The local Ethics Committee for Research approved all the procedures.

\section{Experimental Groups}

The animals were randomly distributed into four experimental groups ( $\mathrm{n}=5$ animals/group): Control $18=$ Non-diabetic rats killed at day 18 of pregnancy; Control $21=$ Non-diabetic rats killed at day 21 of pregnancy; Diabetic $18=$ Diabetic rats killed at day 18 of pregnancy; and Diabetic $21=$ Diabetic rats killed at day 21 of pregnancy.

\section{Experimental design}

The sequence for the severe diabetes and pregnancy was divided into four periods: adaptation, diabetogenesis, mating and pregnancy (de Souza et al. 2009). The diabetic state was induced on female rats by streptozotocin (STZ SIGMA Chemical Company, St. Louis, MO, USA), STZ was dissolved in a citrate buffer $(0.1$ $\mathrm{mol} / \mathrm{l}, \mathrm{pH}$ 6.5) and administered by intravenous injection at a dose of $40 \mathrm{mg} / \mathrm{kg}$ body weight. Nondiabetic rats only received citrate buffer. Blood glucose concentrations were measured seven days after STZ injection. For inclusion criteria, it was considered as diabetic state when the blood glucose concentration was superior to $200 \mathrm{mg} / \mathrm{dL}$ and as normoglycemic state (non-diabetic) when the rats presented glycemia inferior to $120 \mathrm{mg} / \mathrm{dL}$ (Calderon et al. 1992). After the diabetogenesis period, adult female rats were mated overnight with non-diabetic male rats. The morning when spermatozoa were found in the vaginal smear was designated gestational day 0 (Damasceno et al. 2008).

During the pregnancy, the females were maintained in individual cages. In the mornings of days $1,7,14$ and 18 or 21 , the glycemia was determined by a specific glucosemeter (Blood Glucose Monitoring Test Strips Ultra +, HDI Home Diagnostics, Inc, Florida, EUA). It was considered pregnancy glycemic mean (GM) the arithmetic mean obtained by the sum of all the glucose levels measured, divided by their total 
(four). At day 18 or 21 of pregnancy, rats were anesthetized and killed. Then, laparotomy was performed to remove the uterine horns and subsequent weighing of individual live fetuses and placentas.

\section{Fetal weight classification and placental index}

Following fetal weighing, each fetus was classified by the mean $\pm 1.0 \mathrm{x}$ Standard deviation (SD) according to the mean values of fetal weights of the respective control group. The fetuses were as small for pregnancy age (SPA) when weight was lower than control mean - 1.0 x SD; appropriate for pregnancy age (APA) when weight was included in control mean $\pm 1.0 \times \mathrm{SD}$; and large for pregnancy age (LPA) when weight was greater than control mean $+1.0 \times$ SD. The APA and LPA fetuses were grouped and identified as non-SPA (N-SPA). The placental index was calculated by the ratio between placental and fetal weight (de Souza et al. 2009).

\section{Tissue collection and processing}

The placentas were fixed in $10 \%$ buffered formalin for $24 \mathrm{~h}$. Samples were routinely processed for paraffin embedding. Sections $(5 \mu \mathrm{m})$ were cut and stained with hematoxylin and eosin for histological examination. From each tissue block at least one consecutive section of $3 \mu \mathrm{m}$ were cut for immunohistochemistry.

\section{Immunohistochemical localization of PCNA}

The immunohistochemical technique is described as follow. Tissue sections were deparaffinized and rehydrated. The sections were immersed in $3 \%$ hydrogen peroxide $\left(\mathrm{H}_{2} \mathrm{O}_{2}\right)$ for 10 min to block the endogenous peroxidase activity. Nonspecific staining was eliminated by 20 minutes incubation with normal equine serum. The sections were washed with Tris-buffered saline (TBS) to remove the excess normal serum prior the incubation with the primary antibody (anti-PCNA, Novocastra, USA) for $12 \mathrm{~h}$ in a humid chamber at $4^{\circ} \mathrm{C}$. The antibodies were detected using the Avidin-Biotin Complex (ABC) (Novocastra). The slides were washed with TBS between each step. The color was developed for 4 minutes at room temperature with a freshly prepared solution of 3,3' diaminobenzidine (Sigma Chemical CO, MO, USA), the sections were lightly counterstained with hematoxylin, and then dehydrated and mounted. Positive cells were quantified in five randomly selected fields (magnification 40x -
Leica DMLB) per individual sample. The cell proliferation index in cells $/ \mathrm{mm}^{2}\left(\mathrm{I}_{\mathrm{PCNA}}\right)$ was calculated by the total number of PCNA positive cells found in the five fields measured, divided by the circular area in $\mathrm{mm}^{2}$.

\section{Tunel assay}

DNA strand breaks were detected by the TUNEL assay. Briefly, de-waxed and rehydrated placental sections were boiled in $10 \mathrm{mM}$ citrate buffer, $\mathrm{pH}$ 6.0 , in microwave for $10 \mathrm{~min}(1300 \mathrm{~W})$. The samples were pretreated with proteinase $\mathrm{K}$ (2 $\mathrm{mg} / \mathrm{mL}$ ) in $10 \mathrm{mM}$ Tris-buffer, $\mathrm{pH} 8.0$, for $20 \mathrm{~min}$ at $37^{\circ} \mathrm{C}$, washed in phosphate-buffered saline (PBS, Sigma Chemical Co, St. Louis, MO, USA) and incubated in a reaction mixture containing terminal deoxynucleotidyl transferase (TdT) and dUTP (fluorescein-labeled deoxyuridinetriphosphate) in a humidity chamber for $1 \mathrm{~h}$, at $37^{\circ} \mathrm{C}$ and then incubated with Blocking solution (3\% $\mathrm{H}_{2} \mathrm{O}_{2}$ in methanol) for $10 \mathrm{~min}$ at room temperature. Finally, DAB substrate was added for coloration (10 $\mathrm{min}$ at room temperature) and hematoxylin was used for counterstained. The samples was dehydrated and mounted. The apoptotic index $/ \mathrm{mm}^{2}\left(\mathrm{I}_{\mathrm{TUNEL}}\right)$ was calculated by the total number of apoptotic cells found in 25 fields measured, divided by the circular area in $\mathrm{mm}^{2}$.

\section{Statistical analysis}

Maternal glycemia, fetal and placental weight, placental index, fetal weight classification, cell proliferation and apoptosis were analyzed by the Mann-Whitney Test (Zar 1984). For correlation analysis, the Spearman correlation coefficient (Snedecor and Cochran, 1980) between the indexes of cell proliferation (PCNA) and apoptosis (TUNEL) with the fetal weights and the glycemic mean of pregnancy was used. The limit of significance for all results was $95 \%(\mathrm{p}<0.05)$.

\section{RESULTS}

The diabetic rats presented mean levels of glycemia significantly higher than control rats in all analyzed moments (Fig. 1). The fetal weights of diabetic rats were lower, the placentas showed higher weight and increased placental index as compared to control rats at days 18 and 21 of pregnancy (Table 1). The cell proliferation index (PCNA) and apoptosis (TUNEL) remained 
unchanged from day 18 to 21 of pregnancy in rats of the control group. Diabetic rats presented reduction of the PCNA and TUNEL indexes from day 18 to 21 , and these values were lower compared to control groups (Fig. 2). The percentage of SPA fetuses was higher at days 18 $(64 \%)$ and $21(100 \%)$ in diabetic rats (Table 2). At day 21 of pregnancy, the diabetic rats presented lower PCNA and TUNEL indexes in the placentas of SPA fetuses when compared with control 21 rats. The comparison between the PCNA and TUNEL indexes in placentas of SPA fetuses did not differ from N-SPA fetuses into the same experimental group (control or diabetic) at the similar period of pregnancy (18 or 21) (Table 2). TheSpearman correlation coefficients between the PCNA and TUNEL in the control group at day 18 and 21 of pregnancy were -0.29 and 0.22 , respectively. In diabetic 18 and 21 groups, the correlation coefficients were, respectively, 0.21 and -0.02 (Fig. 3). The Spearman correlation coefficients between the PCNA and TUNEL with the fetal weight and the maternal glycemic mean were not different between the control and diabetic groups (Table 3).

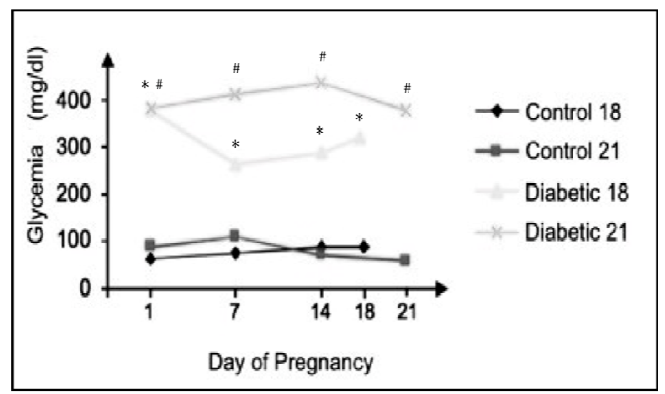

Figure 1 - Evolution of maternal glycemia $(\mathrm{mg} / \mathrm{dL})$ of control and diabetic groups at days 18 and 21 of pregnancy.

* $\mathrm{p}<0.05$ - significant statistically difference compared to control group (day 18).

\# $\mathrm{p}<0.05$ - significant statistically difference compared to control group (day 21).

Table 1 - Fetal weight, placental weight and index of rats from control and diabetic groups at days 18 and 21 of pregnancy.

\begin{tabular}{lcccc} 
& \multicolumn{2}{c}{ Control } & \multicolumn{2}{c}{ Diabetic } \\
\cline { 2 - 5 } & $\mathbf{1 8}$ & $\mathbf{2 1}$ & $\mathbf{1 8}$ & $\mathbf{2 1}$ \\
\hline Fetal weight & $1.52 \pm 0.17$ & $4.82 \pm 0.32^{*}$ & $1.24 \pm 0.21$ & $3.47 \pm 0.39^{\#}$ \\
Placental weight & $0.49 \pm 0.07$ & $0.52 \pm 0.07^{*}$ & $0.59 \pm 0.10$ & $0.74 \pm 0.17^{\#}$ \\
Placental index & $0.28 \pm 0.04$ & $0.11 \pm 0.02^{*}$ & $0.47 \pm 0.13$ & $0.21 \pm 0.06^{\#}$ \\
\hline
\end{tabular}

Data presented as mean \pm standard deviation.

* $\mathrm{p}<0.05$ - significant statistically difference compared to control group (day 18 ).

\# $\mathrm{p}<0.05$ - significant statistically difference compared to control group (day 21).

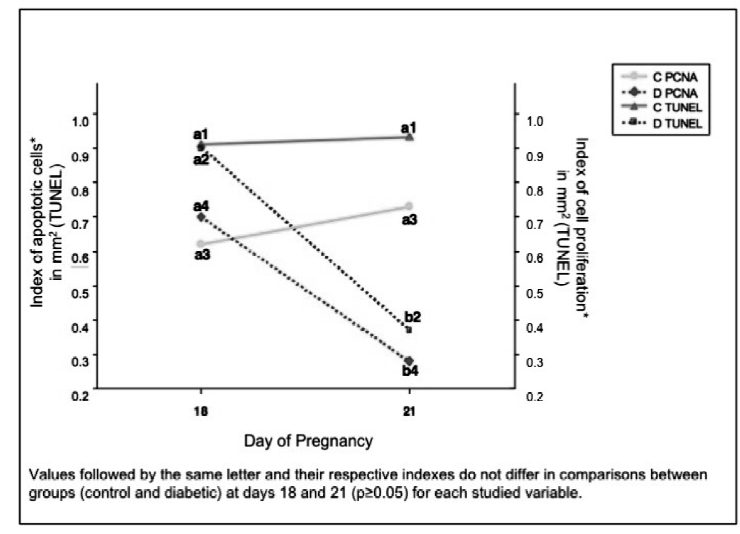

Figure 2 - Evolution of the cellular proliferation and apoptosis $\left(\mathrm{mm}^{2}\right)$ in the placentas of control and diabetic groups at days 18 and 21 of pregnancy. 
Table 2 - Percentage (\%) of fetuses classified as small for pregnancy age (SPA) and non-small for pregnancy age (N-SPA), cell proliferation $\left(\mathrm{I}_{\mathrm{PCNA}}\right)$ and apoptosis $\left(\mathrm{I}_{\mathrm{TUNEL}}\right)$ indexes $/ \mathrm{mm}^{2}$ in the placentas of rats from control and diabetic groups.

\begin{tabular}{lcccc}
\hline & \multicolumn{2}{c}{ Control } & \multicolumn{2}{c}{ Diabetic } \\
\hline SPA & $\mathbf{1 8}$ & $\mathbf{2 1}$ & $\mathbf{1 8}$ & $\mathbf{2 1}$ \\
\%SPA & 12.0 & 8.0 & $64.0^{*}$ & $100.0^{\#}$ \\
I $_{\text {PCNA }}$ & $0.71 \pm 0.32$ & $0.82 \pm 0.14$ & $0.71 \pm 0.27$ & $0.28 \pm 0.09^{\#}$ \\
I $_{\text {TUNEL }}$ & $0.88 \pm 0.06$ & $0.84 \pm 0.13$ & $0.93 \pm 0.14$ & $0.37 \pm 0.10^{\#}$ \\
N-SPA & & & & $0.0^{\#}$ \\
\%N-SPA & 88.0 & 92.0 & $36.0 *$ & - \\
I $_{\text {PCNA }}$ & $0.61 \pm 0.25$ & $0.73 \pm 0.22$ & $0.68 \pm 0.23$ & - \\
I $_{\text {TUNEL }}$ & $0.92 \pm 0.15$ & $0.93 \pm 0.17$ & $0.85 \pm 0.15$ & \\
\hline
\end{tabular}

Data presented as mean \pm standard deviation.

$* p<0.05$ - significant statistically difference compared to control group (day 18).

\# $\mathrm{p}<0.05$ - significant statistically difference compared to control group (day 21).
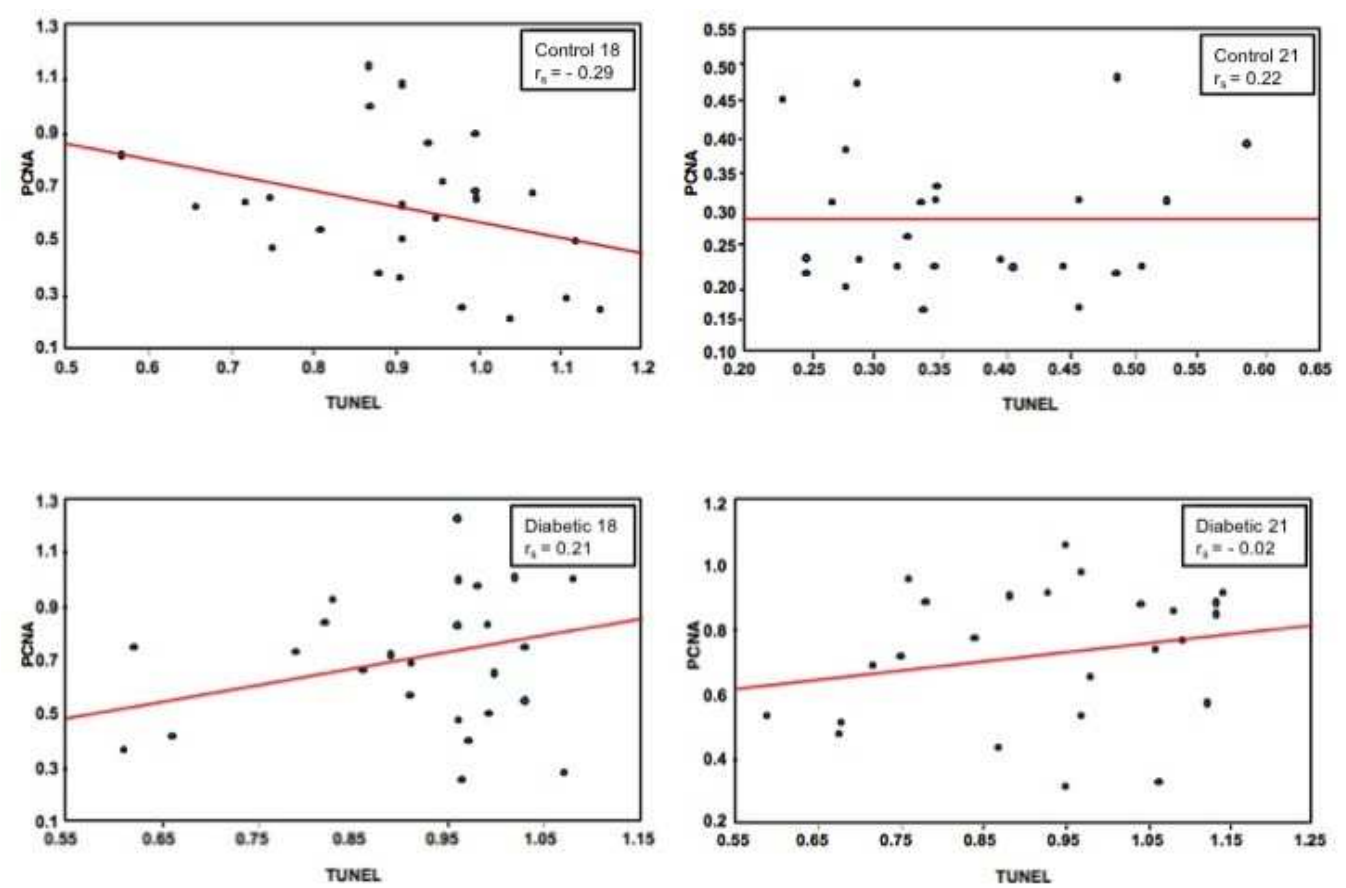

Figure 3 - Spearman correlation coefficient between cellular proliferation (PCNA) and apoptosis (TUNEL) in the placentas of control and diabetic groups at days 18 and 21 of pregnancy.

Table 3 - Spearman correlation coefficient $\left(\mathrm{r}_{\mathrm{S}}\right)$ with fetal weight $(\mathrm{g})$ and maternal glycemic mean $(\mathrm{GM}-\mathrm{mg} / \mathrm{dL})$ at days 18 and 21 of pregnancy of rats from control and diabetic groups.

\begin{tabular}{|c|c|c|c|c|}
\hline & \multicolumn{2}{|c|}{ Control } & \multicolumn{2}{|c|}{ Diabetic } \\
\hline & 18 & 21 & 18 & 21 \\
\hline \multicolumn{5}{|l|}{ PCNA } \\
\hline $\mathrm{r}_{\mathrm{S} \text { PCNAxFetal weight }}$ & 0.07 & 0.19 & -0.20 & -0.09 \\
\hline $\mathrm{r}_{\mathrm{S} \text { PCNAxGM }}$ & 0.45 & -0.08 & -0.10 & -0.09 \\
\hline Apoptosis & & & & \\
\hline $\mathrm{r}_{\mathrm{S}}$ TUNELxFetal weight & 0.08 & 0.45 & -0.23 & -0.29 \\
\hline $\mathrm{r}_{\mathrm{S} \text { TUNELxGM }}$ & 0.10 & 0.002 & 0.35 & -0.26 \\
\hline
\end{tabular}




\section{DISCUSSION}

In the present study, the STZ-induced severe diabetic rats presented $100 \%$ of fetuses classified as SPA at day 21 of pregnancy, characterizing IUGR. These rats presented decreased PCNA and TUNEL indexes from day 18 to 21 of pregnancy showing that the placental cell decreased its proliferation and apoptosis capacity at term pregnancy. As the placenta grows and matures, histopathological changes occur that suggest an increased efficiency of transport to satisfy the metabolic demands of fetal growth. In cases of IUGR, this mechanism is altered and the fetus does not develop (Smith et al. 1997 ).

Calderon et al. (1999) observed that the placentas of rats with severe diabetes had an increased DNA content. However at present study showed a decreased PCNA expression, which could be related to a delay in DNA replication.

An abnormal level of apoptosis also has been correlated with a great variety of gestational pathologies such as in the placentas of abortions, ectopic pregnancy, intrauterine growth retardation, post-term pregnancy, preeclampsia and maternal hypertension syndrome (Halperin et al. 2000; Leung et al. 2001; Smith et al. 1997b). Hyperglycemia modulates the expression of apoptosis regulatory genes in the pre implantation blastocyst stage (Moley 2001) and is able to inhibit the proliferation and to change the mitochondrial activity in trophoblast cell lines (Weiss et al. 2001). Pampfer (2000) showed some anti-apoptotic signals such as TGF- $\alpha$ and other pro-apoptotic, such as oxygen free radicals. In the present study, it was observed that the maternal glycemia did not correlate with reduced apoptosis and cell proliferation indexes. However, reactive oxygen species produced as a result of exposure to hyperglycemia in diabetes, decreased the apoptotic index of the placental tissues in comparison with control pregnancies (Burleigh et al. 2005). This could be confirmed by other studies where severe diabetic rats presented exacerbated oxidative stress (Damasceno et al. 2002; Volpato et al. 2008), which could be a pro-apoptotic factor in the present investigation.
Sgarbosa et al. (2006) showed that hyperglycemia could be a key factor evoking apoptosis in the placental trophoblast, and therefore, was relevant to diabetic placenta function. Controversially, data from the literature also supported opposite results. Burleigh et al. (2004) did not find differences in cell death rates among the trophoblast compartments of five diabetic and normoglycemic placentas. According to Chan et al. (1999), the inverse relationship between the indexes of cell proliferation and apoptosis in the first trimester of pregnancy highlighted the active process of remodeling the trophoblast.

Despite the severe diabetes as a model of IUGR, the pathophysiology of this restriction is controversial. Crocker et al. (2001) showed that the in vitro hypoxia is a trigger factor of apoptosis in the placenta. The excessive apoptosis may cause reduction in placental size and excessive extrusion of trophoblastic material into the maternal circulation. In rats with severe diabetes, fetal weight was lower, the placenta was large and the apoptosis index was low, suggesting that this model of IUGR was metabolic and not hypoxic. There was no passage of nutrients to the fetus because the membrane was thick and insufficient in its nutritional function.

These findings could have interesting clinical correlation in the sudden death of fetuses of diabetic women, not detected by the methods of evaluation of fetal welfare that, mostly, analyzed the hypoxic model. The reduction in the count of fetal movements was an important investigative method in the evaluation of fetal welfare in diabetes and seemed to demonstrate the placental metabolic catatonia.

Thus, the present findings suggested that the PCNA and TUNEL indexes were not correlated to maternal hyperglycemia. The placental apoptosis and cell proliferation indexes did not interfere with the presence of intrauterine growth restriction.

\section{ACKNOWLEDGEMENTS}

We thank to CAPES, Brazil for financial support and to all who contributed to improve this work. 


\section{REFERENCES}

Benirschke K, Kaufmann P. Pathology of the human placenta. 4th ed. New York: Springer; 2000.

Budd RC. Death receptors couple to both cell proliferation and apoptosis. J Clin Invest. 2002; 109(4): 437-41.

Burleigh DW, Stewart K, Grindle KM, Kay HH, Golos, TG. Influence of maternal diabetes on placental fibroblast growth factor-2 expression, proliferation, and apoptosis. J Soc Gynecol Investig. 2004; 11(1): $36-41$.

Calderon IMP, Rudge MVC, Ramos MD, Peraçoli JC. Estudo longitudinal, bioquímico e histoquímico, de placenta de ratas diabéticas: relação com a macrossomia e o retardo de crescimento intra-uterino. Rev. Bras. Ginecol. Obstet.1999; 21(2): 91-8.

Calderon IMP, Rudge MVC, Brasil, MAM, Henry, MACA. Diabete e gravidez experimental em ratas I. Indução do diabete, obtenção e evolução da prenhez. Acta Cir Bras. 1992; 7: 142-6.

Chan CC, Lao TT, Cheung AN. Apoptotic and proliferative activities in first trimester placentae. Placenta. 1999; 20: 223-7.

Cobellis L, De Falco M, Torella M, Trabucco E, Caprio F, Federico E, et al. Modulation of Bax expression in physiological and pathological human placentas throughout pregnancy. In Vivo. 2007; 21(5): 777-83.

Crocker IP, Barrat S, Kaur M, Baker PN. The in vitro characterization of induced apoptosis in placental cytotrophoblast and syncytiotrophoblasts. Placenta. 2001; 22,822-30.

Damasceno DC, Kempinas WG, Volpato GT, Consoni M, Rudge MVC, Paumgartten, FJR. Anomalias Congênitas: Estudos Experimentais. 1st ed. Belo Horizonte: Coopmed; 2008.

Damasceno DC, Volpato GT, Calderon IMP, Rudge, MVC. Oxidative stress and diabetes in pregnant rats. Anim Reprod Sci. 2002; 72: 235-44.

Eriksson UJ, Borg LA, Cederberg J, Nordstrand H, Simán CM, Wentzel C, et al. Pathogenesis of diabetes-induced congenital malformations. Ups $J$ Med Sci. 2002; 105(2): 53-84.

Eriksson UJ, Cederberg J, Wentzel P. Congenital malformations in offspring of diabetic mothers Animal and human studies. Rev Endocr Metab Disord. 2003; 4(1): 79-93.

Halperin R, Peller S, Rotschild M, Bukovsky I, Schneider D. Placental apoptosis in normal and abnormal pregnancies, Gynecol. Obstet. Invest. 2000; 50: 84-7.

Kim SY, Lee SP, Lee JS, Yoon SJ, Jun G, Yonsei IJH. Telomerase and Apoptosis in the Placental Trophoblasts of Growth Discordant Twins. Medical Journal. 2006; 47(5): 698-705.
Kudo T, Izutsu T, Sato T. Telomerase activity and apoptosis as indicators of ageing in placenta with and without intrauterine growth retardation. Placenta. 2000; 21: 493-500.

Leung DN, Smith SC, To, KF, Sahota, DS, Baker PN. Increased placental apoptosis in pregnancies complicated by preeclampsia, Am. J. Obstet. Gynecol. 2001; 184: 1249-50.

Levy R, Nelson DM. To be, or not to be, that is the question. Apoptosis in human trophoblast. Placenta. 2000; 21: 1-13.

Levy R, Smith SD, Yusuf K, Huettner, PH, Kraus FT, Sadovsky Y, et al. Trophoblast apoptosis from pregnancies complicated by fetal growth restriction is associated with enhanced p53 expression. Am J Obstet Gynecol. 2002; 186: 1056-61.

López-Soldado I, Herrera E. Different Diabetogenic Response to Moderate Doses of streptozotocin in Pregnant Rats, and Its Long-Term Consequences in the Offspring. Experimental Diab Res. 2003; 4: 10718.

Moley KH. Hyperglycemia and apoptosis: mechanisms for congenital malformations and pregnancy loss in diabetic women, Trends Endocrinol. Metab. 2001; 141: 78-82.

Pampfer S. Apoptosis in rodent peri-implantantation embryos: differential susceptibility of inner cell mass and trophectoderm cell lineages- a review. Placenta. 2000; 21: 3-10.

Paunesku T, Mittal S, Protić M, Oryhon J, Korolev SV, Joachimiak A, et al. Proliferating cell nuclear antigen (PCNA): ringmaster of the genome. Int J Radiat Biol. 2001; 77(10): 1007-21.

Rudge MV, Calderon IM, Ramos MD, Abbade, JF, Rugolo LM. Perinatal outcome of pregnancies complicated by diabetes and by maternal daily hyperglycemia not related to diabetes. A retrospective 10-year analysis. Gynecol Obstet Invest. 2000; 50(2): 108-12.

Rudge MV, Damasceno DC, Volpato GT, Almeida FC, Calderon IM, Lemonica IP. Effect of Ginkgo biloba on the reproductive outcome and oxidative stress biomarkers of streptozotocin-induced diabetic rats. Braz J Med Biol Res. 2007; 40: 1095-9.

Smith SC, Baker PN, Symonds, EM. Placental apoptosis in normal human pregnancy. Am J Obstet Gynecol. $1997^{\mathrm{a}}$; 177(1): 57-65.

Smith SC, Baker PN, Symonds EM. Increased placental apoptosis in intrauterine growth restriction. Am J Osbst Gynecol. 1997 ; 177(6): 1395-1401.

Snedecor GW, Cochran WG. Statistical methods. 7th ed. Ames: Iowa State University; 1980 pp 505. 
Souza MS, Lima PH, Sinzato YK, Rudge MV, Pereira OC, Damasceno DC. Effects of cigarette smoke exposure on pregnancy outcome and offspring of diabetic rats. Reprod Biomed Online. 2009; 18(4): 562-7.

Volpato GT, Damasceno DC, Rudge MVC, Padovani CR, Calderon IMP. Effect of Bauhinia forficata aqueous extract on the maternal-fetal outcome and oxidative stress biomarkes of streptozotocin-induced diabetic rats. J Ethnopharmacol. 2008; 116(1):131-7.

Zar JR. Bioestatistical analysis. 2nd ed. Englewood Cliffs: Pretence Hall; 1984 pp 718.
Souza MS, Lima PH, Sinzato YK, Rudge MV, Pereira OC, Damasceno DC. Effects of cigarette smoke exposure on pregnancy outcome and offspring of diabetic rats. Reprod Biomed Online. 2009; 18(4), 562-7.

Received: October 07, 2010; Revised: June 06, 2011; Accepted: December 12, 2011. 